\title{
Estimated pressure source on Kozu Island volcano, South Central Japan, from GPS measurements (July 1996-August 1999)
}

\author{
Fumiaki Kimata $^{1}$, Shin-ichi Kariya ${ }^{2}$, Masayuki Fujita $^{3}$, Kunio Matsumoto ${ }^{3}$, Takao Tabei ${ }^{4}$, Jiro Segawa ${ }^{5}$, and Akiko Yamada $^{6}$ \\ ${ }^{1}$ Research Center for Seismology and Volcanology, Graduate School of Science, Nagoya University, Furo, Chikusa, Nagoya 464-8602, Japan \\ ${ }^{2}$ Earth and Planetary Science, Graduate School of Science, Nagoya University, Furo, Chikusa, Nagoya 464-8602, Japan \\ ${ }^{3}$ Hydrographic Department, Maritime Safety Agency, 5-3-1 Tukiji, Minato, Tokyo 104-0045, Japan \\ ${ }^{4}$ Faculty of Science, Kochi University, 2-5-1 Akebono, Kochi 780-8072, Japan \\ ${ }^{5}$ Faculty of Marine Science and Technology, Tokai University, 3-20-1 Orido, Shimizu 424-0902, Japan \\ ${ }^{6}$ Geographical Survey Institute, 1 Kitago, Tsukuba 305-0811, Japan
}

(Received December 31, 1999; Revised August 15, 2000; Accepted August 28, 2000)

\begin{abstract}
Although the Kozu Island Volcano, one of the Izu Islands Volcanoes in the south part Central Japan, is an active volcano, there is no record of the eruption for about 1100 years since the last eruption in 833 A.D. Since 1988, frequent earthquake swarms are observed around the Kozu Island, and the uplift of $2-4 \mathrm{~cm} / \mathrm{yr}$ is observed on the island by tidal observations. Station velocities detected by GPS measurements since 1989 show velocities that differ from the convergent velocity of the Philippine Sea plate calculated from plate motion models. A local GPS network with 12 stations is occupied around the volcano, and the GPS measurements are repeated every about six month since July 1996. Inflated deformation of $2-4 \mathrm{~cm} / \mathrm{yr}$ are detected from the GPS measurements and the pressure source is estimated to be located in the northeastern part of the island at a depth of $2.1 \mathrm{~km}$ using Mogi solution. Negative gravity changes of more than 30 microgal are also measured above the pressure source in the period November 1998 to July 1999 , consistent with uplift.
\end{abstract}

\section{Introduction}

As shown in Fig. 1, there are many volcanoes in the Izu Islands, located in the south part of Central Japan, above the subduction zone of the Philippine Sea (PHS) plate. IzuOshima and Miyake Island Volcanoes have erupted in the last 20 years. Kozu Island Volcano, also one of the Izu Islands Volcanoes, has no record of eruption for 1100 years since a large eruption in 838. As Kozu Island Volcano is mainly constructed of Rhyolite magma, eruptions would be destructive (Taniguchi, 1977). In the eruption in 833, almost all villages on Kozu Island were completely destroyed.

Because Kozu Island is located on the PHS plate, Kimata et al. (1994) indicated GPS measurements on Kozu Island in 1989 as one site of the Izu Islands GPS Campaigns to measure the convergence vector of the PHS plate (Seno et al., 1993). GPS measurements were made on other Izu Islands such as Hachijo and Miyake Islands. Displacement velocities detected from the campaigns show a good consistency with the convergence mode at the Hachijo GPS site, but a discrepancy at the Kozu Island site.

Earthquake swarms have been observed in and around the Kozu Island almost every year since 1989. Earthquakes of magnitude 5 have occurred and have caused some damage in the island.

Although the tidal observations at the Kozu Port have a large noise signal caused by the meander of the Kuroshio

Copy right (C) The Society of Geomagnetism and Earth, Planetary and Space Sciences (SGEPSS); The Seismological Society of Japan; The Volcanological Society of Japan; The Geodetic Society of Japan; The Japanese Society for Planetary Sciences.
Current in this region, the tidal observations suggest an uplift of $2-4 \mathrm{~cm} / \mathrm{yr}$ for the last 10 years (HDMSA, 1999). Large uplifts are also observed by GPS measurements at GSI Kozu site (Polonska et al., 1996).

We started GPS measurements of the local network in 1966 on Kozu Island to measure local deformation and volcano deformation (Kimata et al., 1999). In this paper we discuss the pressure source responsible for the ground deformation that was detected by the GPS measurements.

\section{Measurements}

Before our GPS Campaign, three continuous GPS stations existed, two by Geographical Survey Institute (GSI, 1999a) and one by Nagoya university. Because of limited commercial electric supply, the continuous stations are located only on the west coast area of the island. We set 11 benchmarks for the GPS network between July 1996 and August 1998 (Kimata et al., 1999). The locations of the GPS sites are shown in Fig. 1.

We have repeated GPS measurements at the network seven times: July 1996, January and November in 1997, August 1998 and February and August in 1999. In this paper we did not analyze the data in February 1999, so we skip over the result from February 1999. Measurements are collected during 12 hours observation sessions once or twice for each site with Trimble 4000SSi receivers. Sometimes accesses to the sites are impossible due to the road collapses.

The continuous GPS station by GSI (GSI station in Fig. 1) is fixed as the reference site in the period July 1996 to August 


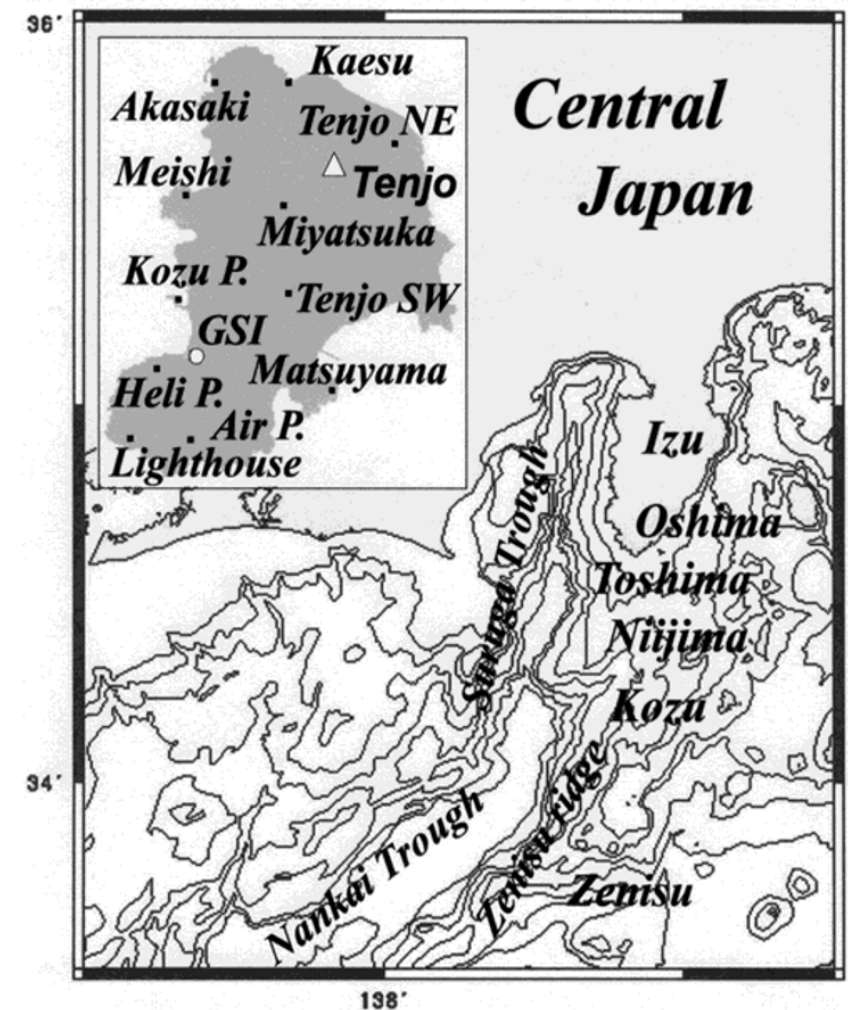

Fig. 1. Location map of Kozu Island and GPS sites in the Kozu Island. Mt. Tenjo is the main peak of the Kozu Island Volcano. BMs of GPS network and continuous GPS measurement site are shown as closed and open circles respectively.

1999. Because of the short distance (less than $5 \mathrm{~km}$ between the benchmarks) on Kozu Island, we processed the GPS data with an L1-only solution. We used Trimble software and the IGS precise orbits.

Figure 2 shows the coordinate changes at the Akasaki and Meishi sites observed by our GPS measurements through the period. It is clear that both sites are shifting eastward with respect to the GSI site with speeds of $3.3 \mathrm{~cm} / \mathrm{yr}$ at the Akasaki site and $2.0 \mathrm{~cm} / \mathrm{yr}$ at the Meishi site most constantly with time (Kimata et al., 1999).

Figure 3 shows the horizontal vectors at the stations with respect to the GSI site for each campaign. From Fig. 3, the inflationary deformation is prominent on the Kozu Island amounting to $2-4 \mathrm{~cm} / \mathrm{yr}\left(2-4 \times 10^{-5} / \mathrm{yr}\right)$ in the northern part of the island.

\section{Pressure Source}

The Mogi solution (Mogi, 1958) is effective at estimating the location and magnitude of the pressure source from ground deformation observation. In our case, we calculate the horizontal displacements with respect to the GSI site. However the GSI site is not stable. Horizontal vectors of $2-3 \mathrm{~cm} / \mathrm{yr}$ toward the west are detected from GPS measurements between Kozu Island and the Tokai region (Kimata et al., 1999; GSI, 1999b). These horizontal vectors are composed of two deformation sources. One of the deformation sources is the convergence of the PHS plate, and the other is local deformation within the island.

Kimata et al. (1999) estimated the local deformation at the
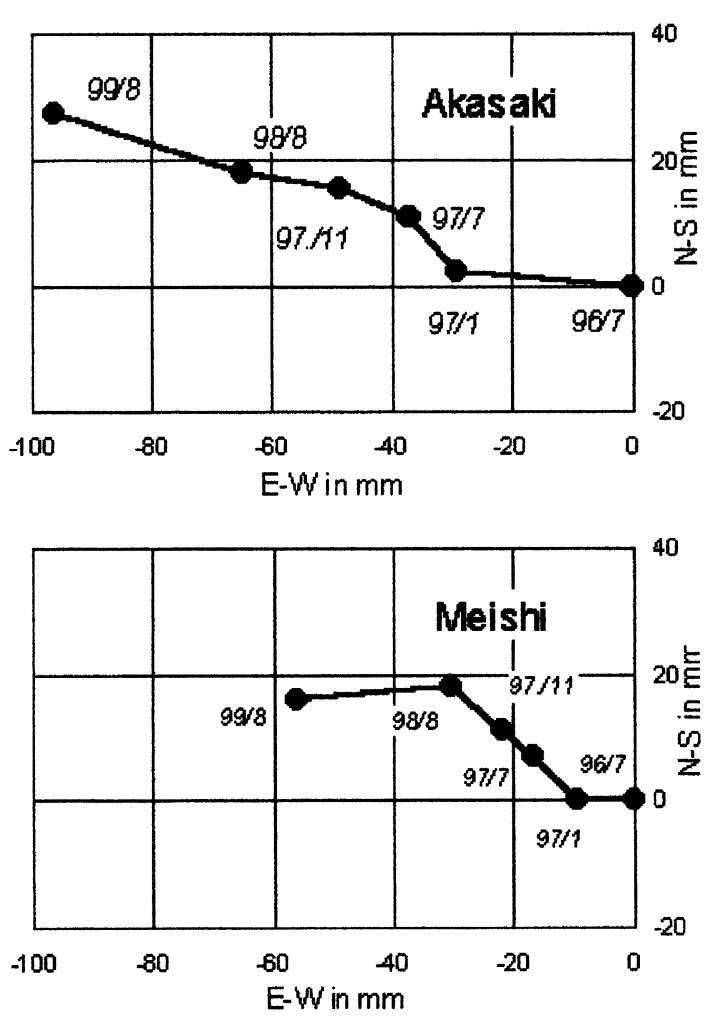

Fig. 2. Changes of the coordinates at Akasaki and Meishi GPS sites in the period July 1996 to August 1999. The coordinate at GSI site is fixed through the observation period.

GSI site as a residual of the displacement vector observed by GPS measurements and calculated by the plate model (Seno et al., 1993; Kotake et al., 1998). The local deformation is a vector of $42 \mathrm{~mm} / \mathrm{yr}$ with direction of N44W. However, Tabei et al. (1999) suggests that the convergent vector of the PHS plate is episodic in the plate boundary region based on GPS measurements at Zenisu Reef. As shown as in Fig. 1 Zenisu Reef is located $50 \mathrm{~km}$ south of Kozu Island and $50 \mathrm{~km}$ from the plate boundary.

In this paper, the horizontal vectors at GPS sites in the island, $V$ are calculated as a following equation,

$$
V=V_{\text {obs }}+V_{\text {calGSI }}
$$

$V_{\text {obs }}$ is the displacement vector observed at the sites with respect to the GSI site, and $V_{\text {calGSI }}$ is the displacement vector at the GSI site calculated from the Mogi solution. We search for the location and magnitude of the pressure source that minimizes the residual of the vectors estimated from the model and $V$.

Figure $4 \mathrm{~A}$ shows the location of the estimated pressure source. The pressure source is estimated to be located $4 \mathrm{~km}$ northeastward of the GSI site at a depth of $2.1 \mathrm{~km}$ in the period August 1998 to August 1999. It is located under the northeast part of the island. We also show the station vectors observed and calculated from the source in Fig. 4A. The horizontal velocity at the GSI site is in general agreement with the result by Kimata et al. (1999).

Figure 5 shows the vertical ground deformation observed and calculated from the pressure source model according to the distance from the source. Uplifts observed at the 


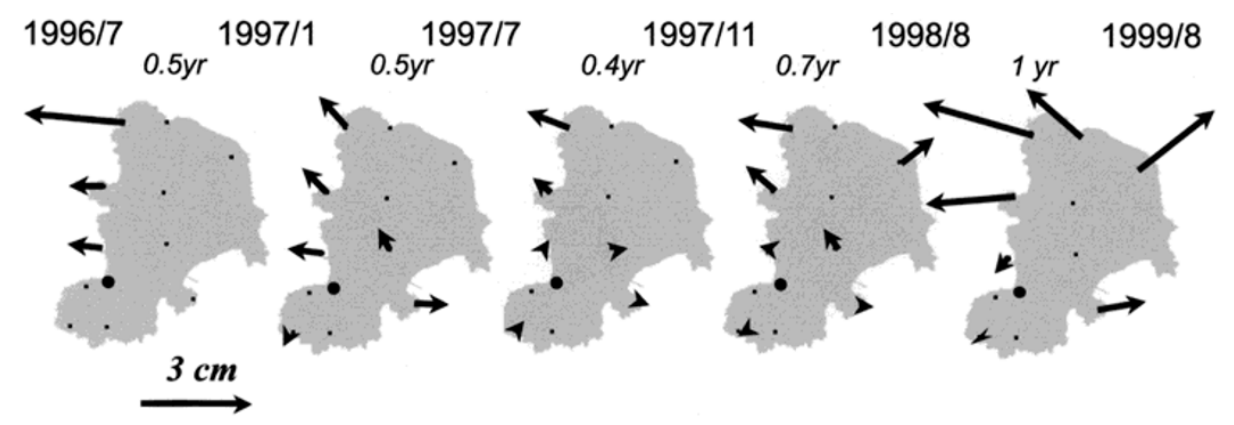

Fig. 3. Horizontal vectors observed at GPS sites in each GPS campaign period. The result observed in February 1999 is skipped. Kozu GSI station, as shown as closed circle, is fixed in the observation period.

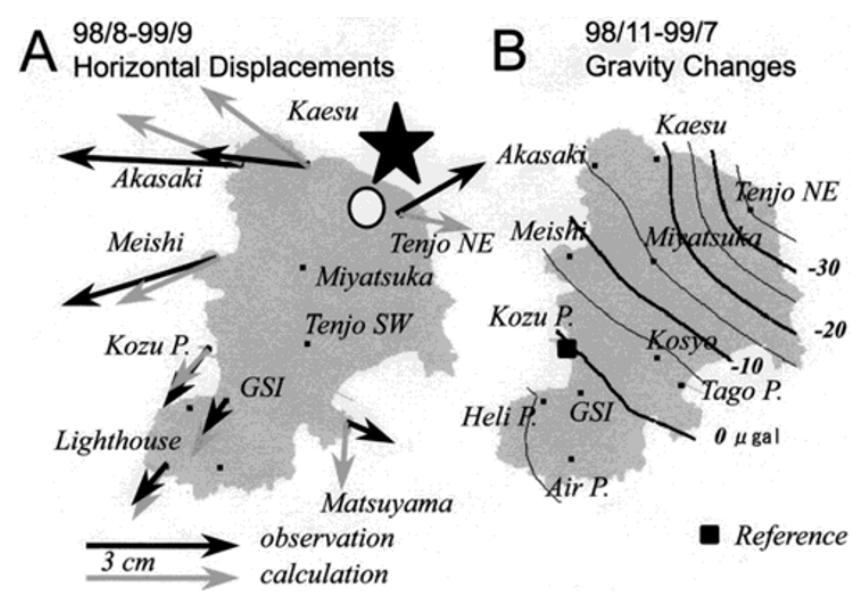

Fig. 4. The location of the pressure source and gravity change on Kozu Island. A: The location of the pressure source and horizontal vectors observed (shown as closed arrows) and calculated (shown as gray arrows) from the source model. The pressure source (shown as open circle) is estimated by the Mogi solution has a depth of $2.1 \mathrm{~km}$. Hypocenter of the earthquake on March 14, 1999 (ML: 4.7) is also shown as a star. B: Gravity changes in the Kozu Island in the period January to September in 1999 by Kobayashi et al. (1999). Gravity changes at the GSI station is fixed.

GSI and Akasaki sites by GPS Earth Observation Network (GEONET) (Miyazaki, personal communication) and at six stations observed by HDMSA (1999) are also shown as open triangles and open circles in the figure. Although a pattern of an uplift is apparent in the north part of the island, vertical movements are $10-20 \mathrm{~mm}$ at the sites. The large errors of vertical movements, are due in part to the different observation periods of these measurements, and also the large measurement error caused by tropospheric delay.

A moderate earthquake (ML: 4.7, Depth; $4.5 \mathrm{~km}$ ) occurred in the northern part of the island on March 14, 1999. The location of the hypocenter is plotted in Fig. 4 as a star. Focal mechanism detected by seismological observation indicates a left lateral fault. In Fig. 4, residuals of the observed and calculated horizontal vectors show the left-lateral displacement stretching northeast-soutwestward from the epicenter. We are preparing to discuss a discussion of the coseismic displacements of the earthquake. According to the Earthquake Research Institute (ERI, 1999), the seismicity is active and many epicenters converge in the northeast part of the island
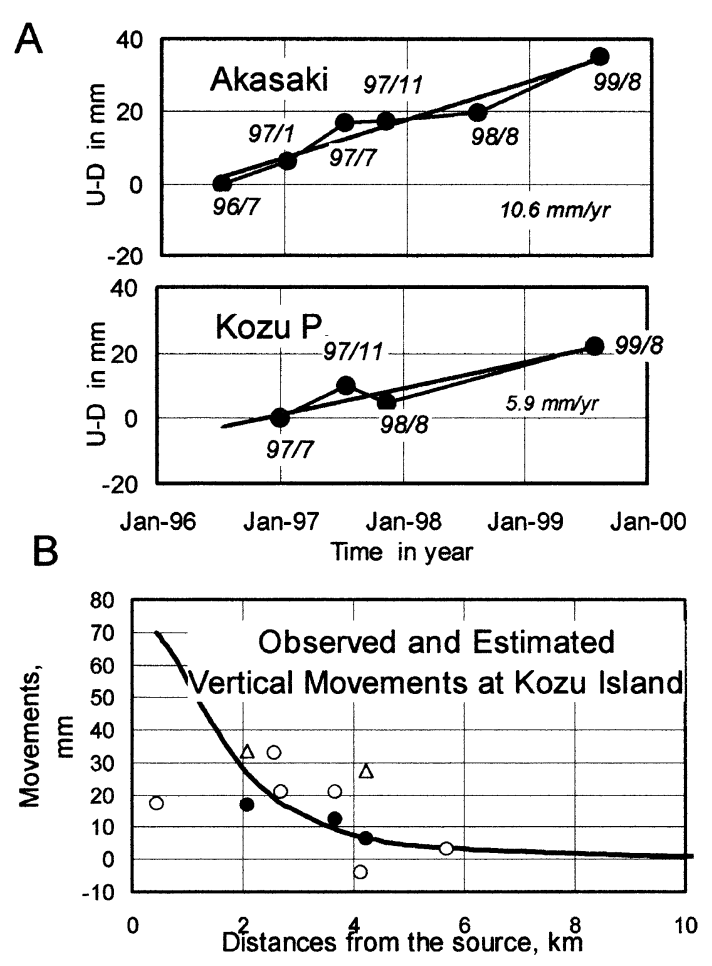

Fig. 5. Time series of vertical movements at the Akasaki and Kozu port sites and Vertical deformation estimated from the model. A: Time series of vertical movements at the Akasaki and Kozu port sites. B: Vertical deformations observed and calculated from the pressure source model. Vertical movements observed by authors, HDMSA (1999) and Miyazaki (personal communication) are also shown as closed circles, open circles and open triangles respectively.

at a depth of $1-5 \mathrm{~km}$.

Figure 4B shows the gravity changes on Kozu Island during the period from November 1998 to July 1999 (Kobayashi et al., 1999). The location of the maximum change more than -30 microgal is coincident with the pressure source determined from the GPS data. We calculate on the horizontal location of uplift more than $70 \mathrm{~mm}$ from the Mogi solution of the GPS displacement, which is consistent with the gravity change.

\section{Conclusion}

We established a local GPS network with 12 stations on Kozu Island Volcano and repeat the GPS measurements about 
every six months since July 1996 to measure volcano deformation. Inflationary ground deformation of $2-4 \mathrm{~cm} / \mathrm{yr}$ is detected in the network through the GPS campaigns. A pressure source is estimated to be located in the northeast part of the island at a depth of $2.1 \mathrm{~km}$ from a Mogi solution of the deformation data. The solution shows the good consistency with the uplift movements of $2-4 \mathrm{~cm} / \mathrm{yr}$ observed at Kozu port by tidal observation (HDMSA, 1999) and GPS measurements by GEONET at the GSI site. Earthquake swarms also are observed frequently in and around the island during the period. Kobayashi et al. (1999) observed negative gravity changes of more than 30 microgal in the northeast part of the island with respect to the GSI site. Inflationary deformation or a magma intrusion model does not explain the negative gravity changes. Although Kozu Island Volcano has no record of the eruption for the late 900 years, the activity at the volcano may be increasing.

Acknowledgments. We express our gratitude to S. Ishida (Kozu Village), T. Sonoda and T. Ishiyama (HDMSA), T. Miyazaki (Tokyo Metropolitan Government), Guesthouse Yosieimaru, H. Aiko (Kagoshima Univ.), R. Kusaba (Kochi Univ.), M. Harada (Kyoto Univ.), M. Okeizumi and N. Yamagata (Tokai Univ.), and $\mathrm{K}$. Matsumoto (Univ. Tokyo) for their assistance of the GPS measurements. Constructive comments made by reviewers Daniel J. Johnson (Central Washington Univ.) and T. Matsushima (Kyushu Univ.) improved the quality of the manuscript.

\section{References}

Earthquake Research Institute, Seismic activity in the Izu Peninsula and its vicinity (Nov. 1998-Jan. 1999, Feb. 1999-Apr. 1999), Report on the Coordinating Committee for Earthquake Prediction, 62, 180-184, 184189, 1999 (in Japanese).

Geographical Survey Institute, Crustal movements in the Izu Peninsula and its vicinity, Report on the Coordinating Committee for Earthquake Pre- diction, 62, 210-223, 1999a (in Japanese).

Geographical Survey Institute, Velocities of horizontal crustal deformations of Japan, Report on the Coordinating Committee for Earthquake Prediction, 62, 515-523, 1999b (in Japanese).

Hydrographic Department Maritime Safety Agency, Crustal movements in Kozu Island, Report on the Coordinating Committee for Earthquake Prediction, 62, 245-249, 1999 (in Japanese).

Kimata, F., M. Satomura, Y. Sasaki, I. Murata, and K. Fuse, GPS measurements in the Tokai region and Izu Hachijo island, Proceedings of the CRCM'93, 225-227, 1994.

Kimata, F., S. Kariya, M. Fujita, K. Matsumoto, T. Tabei, J. Segawa, and A. Yamada, Crustal movements in Kozu Island, Izu Islands in southern Central Japan, detected by GPS measurements (July 1996-November 1997), J. Volcanol. Soc. Japan, 44, 13-22, 1999 (in Japanese with English abstract).

Kobayashi, S., T. Okuda, F. Kimata, and S. Okubo, Relative gravity changes in Kozu Island (Nov. 1998-July 1999)_Evaluation of the accuracy of SCINTREX auto gravity meter-, Program and Abstracts of 92th Meeting of Geod. Soc. Japan, 79-80, 1999 (in Japanese).

Kotake, Y., T. Kato, S. Miyazaki, and A. Sengoku, Relative motion of the Philippine Sea Plate derived from GPS observations and tectonics of the South-Western Japan, J. Seism. Soc. Japan, 51, 171-180, 1998 (in Japanese with English abstract).

Mogi, K., Relations between the eruptions of various volcanoes and the deformations of the ground surface around them, Bull. Earthq. Res. Inst. Univ. Tokyo, 36, 99-134, 1958.

Polonska, D., M. Harigae, T. Tsuiji, M. Murata, and F. Kimata, Observed vertical motion of Kozu-Jima Island using interferometric GPS, Technical Report of National Aerospace Laboratory TR-1322T, 1-9, 1996.

Seno, T., S. Stein, and A. E. Gripp, A Model for the motion of the Philippine Sea plate consistent with NUVEL-1 and Geological data, J. Geophys. Res., 98, 17941-17948, 1993.

Tabei, T., J. Segawa, and F. Kimata, GPS measurements on Zenisu-Reef, Chikyu Monthly, 25, 166-170, 1999 (in Japanese).

Taniguchi, H., Volcanic geology of Kozu-shima, Japan, J. Volcanol. Soc. Japan, 22, 133-147, 1977 (in Japanese).

F. Kimata (e-mail: kimata@seis.nagoya-u.ac.jp), S. Kariya, M. Fujita, K. Matsumoto, T. Tabei, J. Segawa, and A. Yamada 